\title{
Kinetic studies on colonocyte metabolism of short chain fatty acids and glucose in ulcerative colitis
}

\author{
M Rye Clausen, P B Mortensen
}

\begin{abstract}
Short chain fatty acids (SCFAs) are potentially valuable as a topical therapy for distal ulcerative colitis. The mechanism of action is unknown but may involve improved intracellular energy production as previous evidence indicates that colonocyte oxidation of butyrate is impaired in ulcerative colitis. No information is, however, available on human mucosal metabolism of acetate and propionate in either health or disease or the Vmax and $\mathrm{Km}$ values of butyrate oxidation. The aim of the study was to assess the kinetic parameters, Vmax and $\mathbf{K m}$, of the complete oxidation of short chain fatty acids and glucose by human colonocytes and to explore whether a metabolic abnormality could be confirmed in patients with ulcerative colitis. Colonocytes were isolated from surgical specimens obtained from 14 patients with ulcerative colitis and eight control subjects. Incubations were performed in the presence of a concentration range of ${ }^{14} \mathrm{C}$-labelled acetate, propionate butyrate, and glucose. Oxidation rates
\end{abstract} were obtained by quantifying the production of ${ }^{14} \mathrm{CO}_{2}$. Vmax and $\mathrm{Km}$ were calculated by computer fitting of the data to a Michaelis-Menten plot. No significant differences were shown in either Vmax or $\mathrm{Km}$ values of any of the SCFAs or glucose comparing controls and patients with ulcerative colitis. Comparing the results obtained regarding the individual SCFAs, the most striking difference was the considerably lower $\mathrm{Km}$ value of butyrate. The apparent Vmax of acetate tended to be higher than Vmax of propionate and butyrate. $V \max$ of glucose oxidation was significantly lower compared with the Vmax values of SCFA oxidation. The study shows the ability of isolated human colonocytes to utilise each of the three major SCFAs, but does not support a pathogenic role for defective metabolism of butyrate in ulcerative colitis. The considerably lower $\mathrm{Km}$ of butyrate oxidation supports a specific role of butyrate as an energy source for the colonic mucosa in both health and ulcerative colitis.

(Gut 1995; 37: 684-689)

Keywords: colon, fatty acid oxidation, in vitro, kinetic parameters, short chain fatty acids, ulcerative colitis.

Correspondence to: Dr M R Clausen,

Department of Medicine B, Bispebjerg Hospital, Bispebjerg Bakke 23, DK-2400 Copenhagen NV Denmark.

Accepted for publication 29 March 1995

Over the past decade it has become evident that short chain fatty acids (SCFAs) play a greater part in the welfare of colonic mucosa than previously suspected. The principal SCFAs, acetate, propionate, and butyrate, are formed by bacterial fermentation of unabsorbed carbohydrates ${ }^{1}$ and tend to be present in colonic contents in relatively constant concentrations (approximately $100 \mathrm{mmol} / \mathrm{l}$ ) and proportions $(60: 20: 20){ }^{2-4}$ SCFAs are readily absorbed from the colonic lumen, 56 and once inside the colonocytes, the cellular oxidation of SCFAs is considered to be the major energy source for the epithelial cells. ${ }^{7}$

Clinical trials show that SCFA enemas may ameliorate inflammation in distal ulcerative colitis (UC) ${ }^{8-13}$ The potential mechanism by which SCFAs affect the colonic mucosa is unknown, but evidence that butyrate oxidation is impaired in colonocytes isolated from patients with UC has led to the hypothesis that failure of fatty acid oxidation in UC is an expression of an energy deficiency disease of the colonic mucosa. ${ }^{14}$ It has therefore been suggested that local application of higher than normal concentrations of SCFAs may overcome the partial metabolic block in UC by mass action and thereby improve mucosal energy supply. No information, however, is available on the metabolism of acetate and propionate in either health or disease. If the defect of cellular SCFA oxidation is restricted to butyrate the mucosal energy requirements may be met by oxidation of acetate or propionate and irrigation of these two acids may then prove to be the most successful treatment.

Because of both the therapeutic implications as well as potential mechanisms involved regarding disease pathogenesis we found it of interest to investigate the complete oxidation of the three major SCFAs and glucose into $\mathrm{CO}_{2}$ by colonic epithelial cells isolated from patients with UC and control subjects. As previous experiments using isolated rat colonocytes have shown that oxidation rates of SCFAs and glucose varies with substrate concentrations in accordance with MichaelisMenten kinetics, ${ }^{15}$ cell suspensions were incubated in the presence of substrates added in concentrations ranging from $0 \cdot 125 \mathrm{mmol} / 1$ to $2 \mathrm{mmol} / \mathrm{l}$ (SCFAs) or $4 \mathrm{mmol} / \mathrm{l}$ (glucose). The resultant curves obeyed the Michaelis-Menten equation permitting the determination of the kinetic parameters, Vmax and $\mathrm{Km}$.

\section{Methods}

\section{Materials}

Bovine serum albumin (Fraction V), dithio- threitol (DTT), EDTA, and unlabelled D-glucose were obtained from Sigma Chemical (St Louis, MO, USA). Unlabelled 

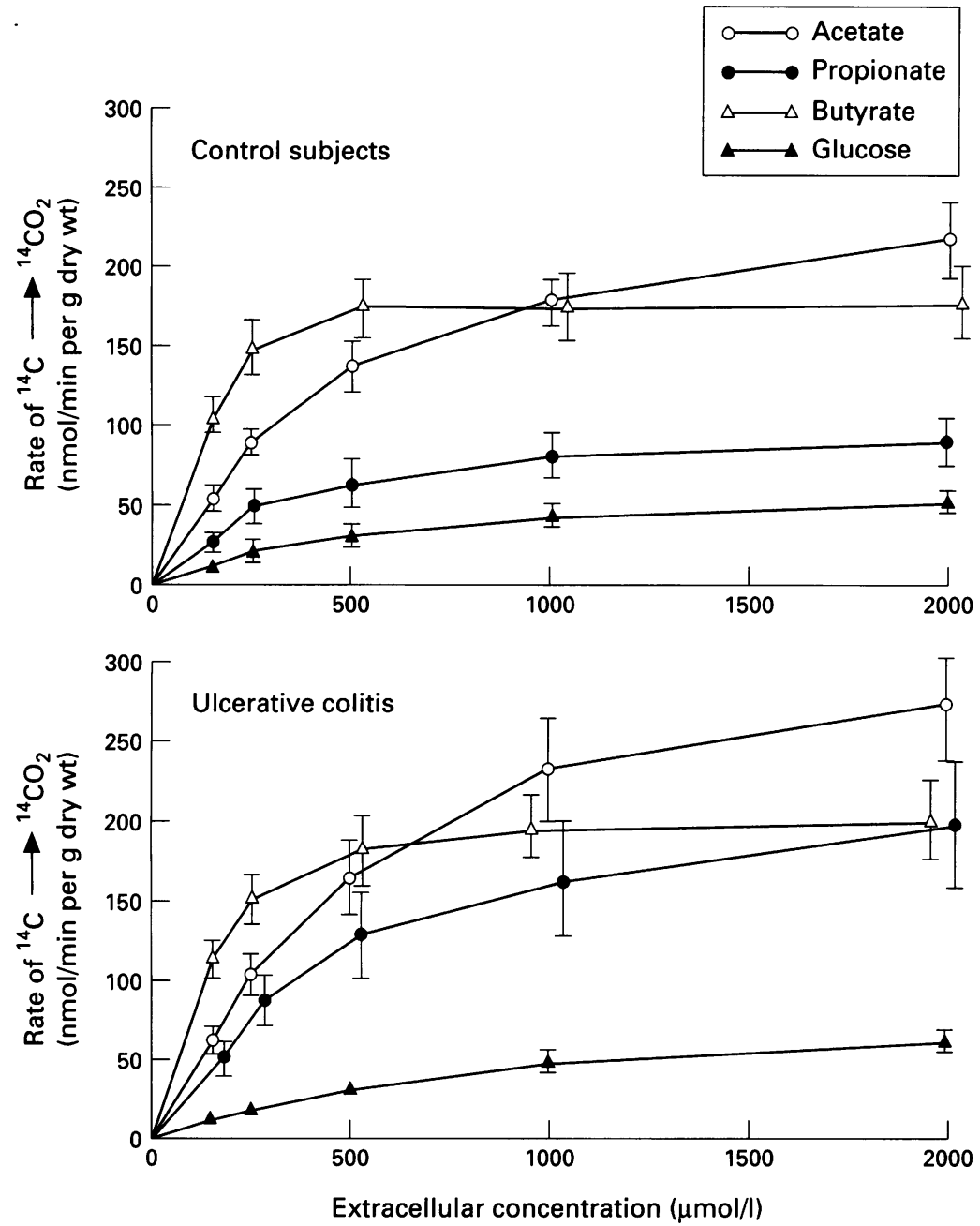

Figure 1: Rate of ${ }^{14} \mathrm{CO}_{2}$ production from ${ }^{14} \mathrm{C}$-labelled acetate, propionate, butyrate, and glucose by colonocytes isolated from control subjects and patients with ulcerative colitis. Values are means (SEM). strips from the muscularis propria with scissors. The strips were cut into $2-3 \mathrm{~cm}$ segments and placed in calcium free Krebs-Henseleit saline ${ }^{16}$ with $5 \mathrm{mmol} / \mathrm{l}$ DTT previously gassed with $\mathrm{O}_{2}$ and $\mathrm{CO}_{2}(19: 1$, vol/vol) for transport to the laboratory.

Isolated cells were prepared as described by Roediger and Truelove, ${ }^{17}$ with the exception that hyaluronidase was omitted. Cell suspensions, $1 \mathrm{ml}$ representing 5-15 $\mathrm{mg}$ dry wt of epithelial cells, were incubated for 40 minutes in conical flasks equipped with a glass centre well. Incubations were performed in $1 \mathrm{ml}$ of Krebs-Henseleit saline containing $2.5 \%$ (wt/vol) bovine serum albumin, $5 \mathrm{mmol} / \mathrm{L} \mathrm{DTT}$, and the appropriate substrates. Labelled substrates were evaluated at concentrations ranging from $0 \cdot 125$ to $2 \mathrm{mM}$ for acetate, propionate, and butyrate, and from 0.125 to $4 \mathrm{mM}$ for glucose. In each experiment, identical incubations were run in parallel from which exogenous substrate was omitted. Flasks without cells were included to correct for volatility of SCFAs. Flasks were gassed with $\mathrm{O}_{2}: \mathrm{CO}_{2}(19: 1, \mathrm{vol} / \mathrm{vol})$ for 15 seconds, stoppered immediately, and shaken at 90 oscillations $/ \mathrm{min}$ in a $37^{\circ} \mathrm{C}$ waterbath. Incubations were terminated by injecting $0.5 \mathrm{ml}$ of $10 \%$ perchloric acid through the stopper into the suspension. In a similar manner, the centre wells were filled with $0.5 \mathrm{ml}$ of $10 \mathrm{M} \mathrm{NaOH}$ to adsorb $\mathrm{CO}_{2}$. The flasks were shaken for a further two hours on ice to allow the labelled ${ }^{14} \mathrm{CO}_{2}$ to diffuse and be trapped, after which $0.1 \mathrm{ml}$ of the adsorbent were transferred in duplicate to counting vials and mixed with $10 \mathrm{ml}$ of scintillation liquid (Ultra Gold, Packard Instrument, Chemical Operations, Groningen, the Netherlands).

acetate, propionate, and butyrate were obtained from BDH Limited (Dorset, UK). Radioactively labelled compounds were obtained from the following sources: $\left[1-{ }^{14} \mathrm{C}\right]-$ acetate and $\left[1-{ }^{14} \mathrm{C}\right]$-propionate from Sigma Chemical (St Louis, MO, USA), $\left[1-1^{14} \mathrm{C}\right]-$ butyrate from Du Pont-NEN Research Products (Boston, MA, USA), and [D-6- $\left.{ }^{14} \mathrm{C}\right]-$ glucose from Amersham (Amersham, UK).

\section{Isolation and incubation of colonocytes}

Colonocytes were isolated from fresh surgical specimens obtained at operations performed for moderate or severe ulcerative colitis $(n=14$; 4 men, 10 women; age $20-75$ years, mean 36 ), carcinoma of the colon $(n=8 ; 1$ man, 7 women; age $46-83$ years, mean 70 ), and paraplegia with severe constipation ( $1 \mathrm{man} ; 73$ years). Originally nine patients were included in the group of colonic cancer. By histological evaluation, however, one patient (female, 72 years) turned out to have Crohn's disease and was therefore not included in the data analysis. In patients with UC, mucosa was stripped from areas with no visible ulcerations, and at least $5 \mathrm{~cm}$ from the carcinoma in patients with colonic cancer. The colonic specimens were washed clear of debris with water, cut open, and pinned out to assist removal of mucosal

\section{Analytical methods}

Radioactivity was counted in a model 4530 Packard TriCarb liquid scintillation spectrometer (Packard Instrument, IL, USA) and counts were corrected for the non-specific activity generated by perchloric acid. Duplicate measurements of dry weights were obtained by drying $1 \mathrm{ml}$ of cell suspension overnight at $65^{\circ} \mathrm{C}$ and subtracting the weight of $1 \mathrm{ml}$ of the albumin containing medium.

\section{Calculations}

Oxidation rates are expressed as nmol per min per gram dry weight of epithelial cells. Generation of $\mathrm{CO}_{2}$ from ${ }^{14} \mathrm{C}$-labelled SCFAs or glucose is calculated from the specific hydroxide. The apparent values of $V \max$ and $\mathrm{Km}$ are calculated by computer fitting of the data to a Michaelis-Menten plot (Enzfitter, RJ Leatherbarrow, Elsevier, Amsterdam).

\section{Statistics}

Data are expressed as means (SEM). Comparisons between different groups were performed by the analysis of variance groups were compared. When a statistically activities and trapped ${ }^{14} \mathrm{CO}_{2}$ in sodium (ANOVA), equivalent to a $t$ test if only two 
Kinetic constants for production of ${ }^{14} \mathrm{CO}_{2}$ from $\left[1-{ }^{14} \mathrm{C}\right.$-labelled SCFAs and $\left[6^{-14} \mathrm{C}\right]-$ labelled glucose by isolated colonocytes

\begin{tabular}{lccccc}
\hline & Acetate & Propionate & Butyrate & Glucose & ANOVA p value \\
\hline Vmax (nmol/min per $g$ dry wt of epithelial cells) & & & \\
Control subjects & $286(27)^{\mathrm{a}}$ & $109(19)^{\mathrm{b}}$ & $187(24)^{\mathrm{c}}$ & $71(8)^{\mathrm{b}}$ & $<10-5$ \\
Ulcerative colitis & $364(54)^{\mathrm{a}}$ & $269(67)^{\mathrm{ab}}$ & $212(25)^{\mathrm{b}}$ & $82(8)^{\mathrm{c}}$ & $10-3$ \\
$t$ Test $(\mathrm{p}$ value) & 0.32 & 0.12 & 0.51 & 0.42 & \\
$K m(\mu$ moll) & & & & & \\
Control subjects & $565(40)^{\mathrm{a}}$ & $369(54)^{\mathrm{b}}$ & $82(10)^{\mathrm{c}}$ & $605(84)^{\mathrm{a}}$ & $<10-5$ \\
Ulcerative colitis & $621(48)^{\mathrm{ab}}$ & $527(94)^{\mathrm{b}}$ & $98(10)^{\mathrm{c}}$ & $713(50)^{\mathrm{a}}$ & $<10-5$ \\
$t$ Test (p value) & 0.45 & 0.28 & 0.30 & 0.25 &
\end{tabular}

Values are expressed as means (SEM).

Means not sharing the same superscript letter within a row are significantly different at $\mathrm{p}<0.05$ (least significant difference) significant result was obtained by the ANOVA $(p<0.05)$, group differences were tested by least significant difference.

\section{Results}

A time course study (20, 40, and 60 minutes) showed that colonocyte oxidation of SCFAs $(2 \mathrm{mmol} / \mathrm{l})$ and glucose $(4 \mathrm{mmol} / \mathrm{l})$ was linear over 60 minutes in both patients with UC and control subjects indicating efficient metabolic performance of isolated cells during the incubation period (40 minutes).

Figure 1 exhibits the rate values of ${ }^{14} \mathrm{CO}_{2}$ production from ${ }^{14} \mathrm{C}$-labelled acetate, propionate, butyrate, and glucose as a function of substrate concentrations in controls and patients with UC. The resultant curves obeyed Michaelis-Menten kinetics for all substrates permitting the determination of the kinetic parameters, Vmax and Km (Table).

The apparent $\mathrm{Vmax}$ and $\mathrm{Km}$ values of SCFAs and glucose oxidation did not differ significantly comparing control subjects and patients with UC (Table). Patients with noninflammatory colonic diseases belonged to a significantly older age group than patients with UC showing that age is no determinant of SCFA metabolism.

In controls, Vmax of acetate (286 (27) $\mathrm{nmol} / \mathrm{min}$ per $\mathrm{g}$ dry wt) was significantly higher than the Vmax of butyrate $(187(24) \mathrm{nmol} / \mathrm{min}$ per $\mathrm{g}$ dry wt), which again was higher than the Vmax values of propionate $(109$ (19) $\mathrm{nmol} / \mathrm{min}$ per g dry wt) and glucose (71 (8) $\mathrm{nmol} / \mathrm{min}$ per g dry wt) - that is, $V \max$, acetate $>V \max$, butyrate $>V \max$, proprionate $=V \max$, glucose . The same pattern was seen in patients with UC, although the Vmax of propionate (269 (67) $\mathrm{nmol} / \mathrm{min}$ per $\mathrm{g}$ dry wt) did not statistically differ from the Vmax of either acetate (364 (54) $\mathrm{nmol} / \mathrm{min}$ per $\mathrm{g}$ dry $\mathrm{wt}$ ) or butyrate (212 (25) $\mathrm{nmol} / \mathrm{min}$ per $\mathrm{g}$ dry $\mathrm{wt}$ ) (Table).

Comparing the $\mathrm{Km}$ values of the individual SCFAs, a considerably lower $\mathrm{Km}$ value of butyrate was found in both controls and patients with UC (Table). In controls, the Km values were all significantly different and in the order of butyrate $(82(10) \mu \mathrm{mol} / \mathrm{l})<$ propionate (369 (54) $\mu \mathrm{mol} / \mathrm{l})<$ acetate $(565(40) \mu \mathrm{mol} / \mathrm{l})$. The $\mathrm{Km}$ value of glucose $(605(84) \mu \mathrm{mol} / \mathrm{l}) \mathrm{did}$ not differ from the $\mathrm{Km}$ value of acetate. In patients with $\mathrm{UC}$, the $\mathrm{Km}$ values of acetate and propionate were not significantly different that is, butyrate $(98(10) \mu \mathrm{mol} / \mathrm{l})<$ acetate $(621$ (48) $\mu \mathrm{mol} / \mathrm{l})=$ propionate $(527$ (94) $\mu \mathrm{mol} / \mathrm{l})$.
As in controls, the $\mathrm{Km}$ value of glucose (713 (50) $\mu \mathrm{mol} / \mathrm{l}$ ) was not significantly different from the $\mathrm{Km}$ value of acetate (Table).

Figure 2 shows the production rates of ATP as a function of substrate concentrations. The values of ATP production are calculated on the basis that complete oxidation of $1 \mathrm{~mol}$ acetate, propionate, butyrate, and glucose provides 10 , 18,27 , and $36 \mathrm{~mol}$ of ATP, respectively. ${ }^{18} \mathrm{At}$ each concentration the production rates of ATP were similar comparing acetate, propionate, and glucose but significantly higher for butyrate in both UC and controls.

\section{Discussion}

The concept of SCFAs being a critical luminal nutrient source for the colonic mucosal cells and of there being a potential 'metabolic block' in UC was originally proposed by Roediger in $1980 .{ }^{7}{ }^{14}$ In cell suspensions of isolated human colonocytes (resection specimens obtained from patients with carcinoma of the colon), butyrate accounted for more than $70 \%$ of the oxygen consumption, and the hypothesis was put forward that fatty acids of anaerobic bacteria are an important source of energy for the colonic mucosa. ${ }^{7}$ In patients with quiescent and acute UC the oxidation rates of butyrate to $\mathrm{CO}_{2}$ and ketones were significantly lower than in control tissues, and the decrease correlated with the state of the disease. ${ }^{14}$ Enhanced glucose and glutamine utilisation compensated for the decreased oxidation of butyrate, as measured by lactate and ammonia production, respectively. It was therefore suggested that failure of fatty acid (butyrate) oxidation in UC is an expression of an energy deficiency disease of the colonic mucosa. ${ }^{14}$

In 1988 Vernia et al ${ }^{19}$ investigated faecal water samples from patients with UC and Crohn's disease. In UC, concentrations of each SCFAs, especially butyrate, were decreased compared with those from healthy controls or Crohn's disease. When patients with UC were classified according to the activity of colitis, concentrations of SCFAs were high in quiescent and mild disease, but significantly decreased in the severe form. ${ }^{20}$ These findings, and the previous finding of impaired butyrate oxidation in colitic cells, ${ }^{14}$ prompted the authors to suggest that restoration of normal luminal concentrations of SCFAs in UC could be considered as a therapeutic manoeuvre.

Clinical results concerning the treatment of distal UC with rectal instillation of SCFAs have indeed been encouraging. Breuer et $a l^{8}$ tested a combination of SCFAs in patients with refractory distal UC. In their open trial, nine of 10 patients who completed the study showed clinical, endoscopic, and histological improvement by the end of six weeks. The authors have recently reported the results of the first 41 patients in an ongoing double blind, placebo controlled trial of SCFA rectal irrigation in patients with left sided UC. ${ }^{13}$ These interim results seem to confirm the earlier uncontrolled findings using the same protocol. In a randomised, prospective comparison of corticosteroid, mesalamine, and 

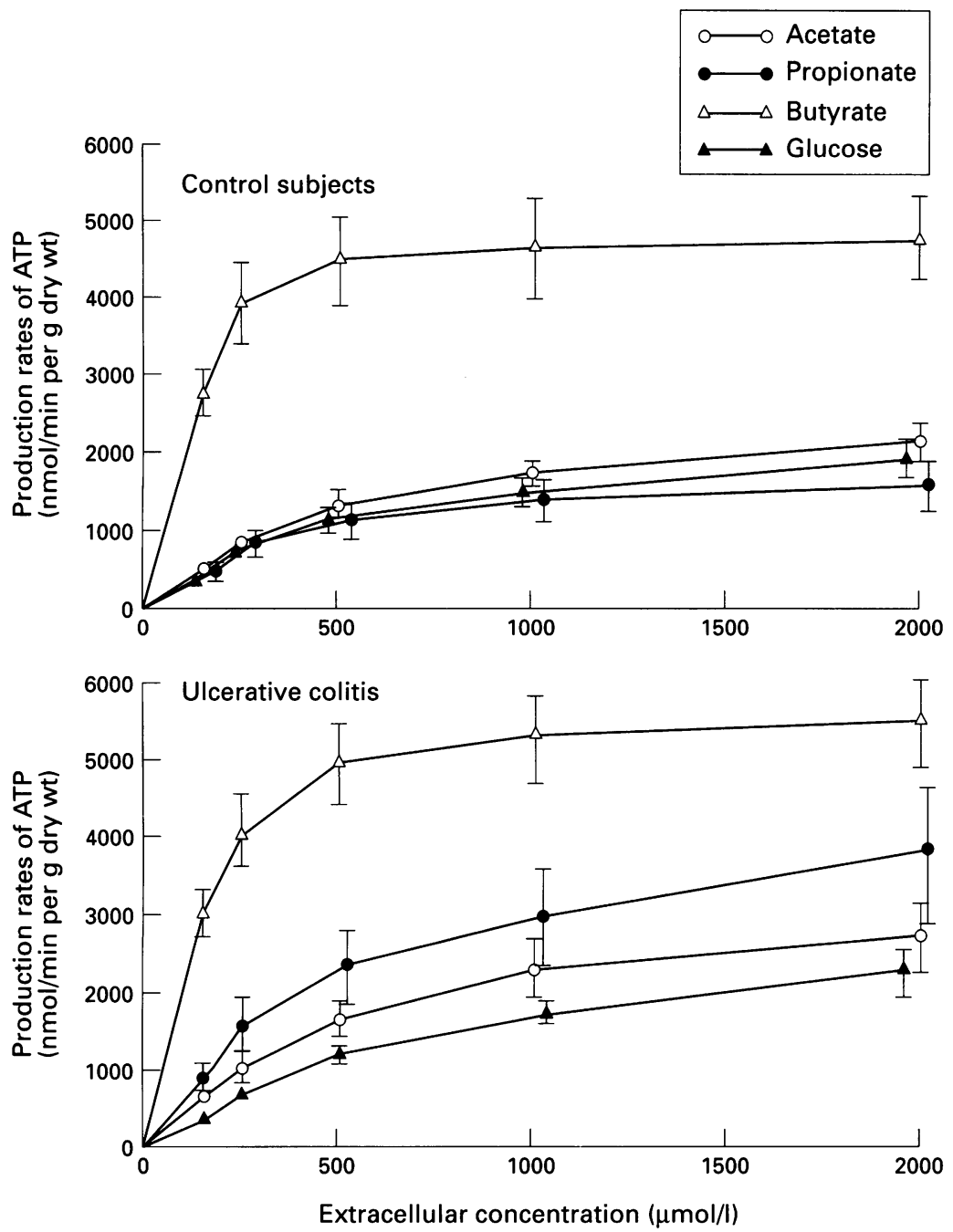

Figure 2: Rate of ATP production from acetate, propionate, butyrate, and glucose by colonocytes isolated from control subjects and patients with ulcerative colitis. Values are means (SEM). patients with severe UC, ${ }^{20}$ others have found that values are normal, 2122 or even increased in this setting. ${ }^{23}$ The last study by Roediger et $a^{23}$ measured luminal concentrations of SCFAs in patients with UC, which were graded according to mucosal changes into mild, moderate, or severe inflammatory activity. Concentrations of acetate, propionate, and butyrate were all increased in severe UC whereas only butyrate concentrations were significantly raised in patients with mild and moderate inflammatory activity. The authors suggested that the persistently raised concentrations of butyrate in all severities of mucosal inflammation could reflect the previously shown inability of butyrate utilisation in UC. ${ }^{14}$ In that case, it would be less plausible that the response of UC to SCFA administration is mediated through increased accessibility of butyrate.

To our knowledge this is the first study to investigate the colonic mucosal metabolism in patients with UC by use of isolated colonocytes since the study performed by Roediger in $1980 .{ }^{14}$ The similar oxidation of butyrate in controls and patients with UC shown by our study is in contrast with the results previously obtained. ${ }^{14}$ With reference to luminal concentrations, Roediger considered butyrate concentrations of $10 \mathrm{mmol} / \mathrm{l}$ as physiological. ${ }^{14}$ By use of separated cells, however, not only the mucosal cell membranes become exposed to the surrounding solution but also the serosal parts, which in vivo are exposed to SCFA concentrations of about $1 / 100$ to $1 / 1000$ of the luminal concentrations, 22425 and recent studies on isolated rat colonocytes ${ }^{15}$ have shown $\mathrm{Km}$ values of SCFA oxidation in the range of $0.2-0.5 \mathrm{mmol} / 1$ indicating that intracellular concentrations may be closer to portal rather than luminal concentrations. The incubations in our study were therefore performed in the presence of extracellular concentrations ranging from 0.125 to $2 \mathrm{mmol} / \mathrm{l}$. The resultant curves obeyed MichaelisMenten kinetics for all substrates permitting the determination of the kinetic parameters, Vmax (maximum rate of metabolism) and $\mathrm{Km}$ (the substrate concentration at which the reaction rate has half its maximum value) showing that the maximum rate of SCFA oxidation by isolated colonocytes is well achieved at concentrations around $2 \mathrm{mmol} / \mathrm{l}$ (Table). The $\mathrm{Km}$ values of acetate, propionate, and butyrate were very similar to the values obtained by isolated rat colonocytes, ${ }^{15}$ and addition of butyrate in concentrations of $10 \mathrm{mmol} / \mathrm{l}$ - that is, about 100 times higher than the $\mathrm{Km}$ value, might be unphysiological. Artefactual abnormalities may therefore be introduced, and toxic effects of sodium butyrate at concentrations above $2 \mathrm{mmol} / 1$ have been reported in cultured human cancer cell lines. ${ }^{26} 27$ If cells from inflamed epithelium are more prone to toxicity, artefactual differences could hypothetically have been introduced in studies using concentrations of butyrate which, according to the obtained $\mathrm{Km}$ values, are unphysiologically high. The presence of increased values of luminal bacterial metabolites (for example, higher than normal and subsequent 'mas action'. The existence of a luminal deficiency of SCFAs has, however, not been universally accepted. Although some authors have shown reduced concentrations of SCFAs in faeces of 
mercapto fatty acids, sulphides) causing specific inhibition of fatty acid oxidation in colonic epithelial cells has been proposed to be the initiating event of the disease process that leads to an immune response and colitis. ${ }^{28} 29$ If this is correct, a more thorough cell wash may have eliminated some inhibitory factor(s), and the discrepancy between our and Roediger's findings might be based on minor differences, for example, cell washing procedure.

By use of a different technique, two further studies have investigated the metabolic performance of colonic epithelial cells in patients with UC. The study by Finnie et al ${ }^{30}$ compared the oxidation of butyrate in mucosal biopsy specimens obtained from patients with longstanding quiescent UC and controls. No differences in butyrate oxidation were established. An explanation for the discrepancy between their and Roediger's findings could be the use of different techniques, The study by Chapman et $a l,{ }^{31}$ however, did in fact show a significantly lower rate of butyrate oxidation in biopsy specimens obtained from patients with quiescent UC. Nevertheless, an important anxiety over the use of biopsy specimens is, in our opinion, that the size of specimens may differ resulting in different proportions of actively metabolising (mucosal cells) and inactive (cells of lamina propria/submucosa) tissue, which may be a problem as the results are expressed per $\mathrm{g}$ protein. ${ }^{30} 31$

This study showed that isolated human colonocytes can utilise each of the major SCFAs. No major differences in the apparent Vmax values of $\mathrm{CO}_{2}$ production from acetate, propionate, and butyrate were seen (Table). In the assessment of the relative importance of the individual SCFAs in the energy generating process, however, the order of energy contribution may be of more relevance. Calculated on the basis that complete oxidation of $1 \mathrm{~mol}$ acetate, propionate, and butyrate provides 10, 18, and $27 \mathrm{~mol}$ ATP, respectively, ${ }^{18}$ a relative order of energy contribution of butyrate $>$ acetate $=$ propionate is found (Fig 2). The importance of butyrate as an energy source for the colonic mucosa is further emphasised by the finding that it had the lowest $\mathrm{Km}$ showing that butyrate may serve as a more readily oxidised fuel than propionate and acetate at low concentrations $(<200 \mu \mathrm{mol} / \mathrm{l})$. In vivo, the colonic mucosa is exposed to very high luminal concentrations of SCFAs, but intracellular concentrations are unknown and may be closer to portal blood concentrations, which are in the range of $114-258 \mu \mathrm{mol} / 1$ for acetate, $32-88 \mu \mathrm{mol} / 1$ for propionate, and 9-29 $\mu \mathrm{mol} / 1$ for butyrate 2425 - that is, remarkably close to the reported $\mathrm{Km}$ values of SCFA oxidation.

No differences in $V \max$ or $\mathrm{Km}$ values of glucose oxidation were found comparing patients with UC and control subjects. In colonocytes isolated from patients with UC, Roediger reported an increased rate of glucose utilisation, measured as lactate production. ${ }^{14}$ The present lack of a corresponding increase in the rate of $\mathrm{CO}_{2}$ production is in agreement with the results of Chapman. ${ }^{31}$ The apparent
Vmax of glucose oxidation was significantly lower compared with the Vmax values of SCFA oxidation. However, assuming that complete oxidation of $1 \mathrm{~mol}$ glucose provides $36 \mathrm{~mol}$ of ATP, ${ }^{18}$ the maximum energy contribution from glucose oxidation is in fact comparable with the energy contribution from acetate and propionate (Fig 2) showing that the energy requirements of human colonocytes may be supported by oxidation of blood borne glucose.

This study has shown the ability of isolated human colonic cells to utilise each of the three major SCFAs. The considerably lower $\mathrm{Km}$ of butyrate oxidation shows that butyrate is metabolised more avidly than acetate and propionate at low concentrations and supports a specific role of butyrate as an energy source for the colonic mucosa. Although other effects of SCFAs than their role as energetic fuels may provide additional explanations as to how they seem to improve UC, the results suggest that SCFA solutions should include butyrate in the treatment of UC, not because increased luminal concentrations may overcome a metabolic block but because butyrate seems to be an excellent fuel for colonocytes in patients with UC.

This work was funded by grants from the Danish Medical Research Council, the Foundation of Olga and Esper Boel, and the Danish Foundation for Advancement of Medical Science. The skilful technical assistance of Bodil Petersen is greatly appreciated.

1 Cummings JH, Macfarlane GT. The control and consequences of bacterial fermentation in the human colon. $f$ Appl Bacteriol 1991; 70: 443-59.

2 Cummings JH, Pomare EW, Branch WJ, Naylor CPE Macfarlane GT. Short chain fatty acids in the human large intestine, portal, hepatic and venous blood. Gut 1987; 28: 1221-7.

3 Mortensen PB, Hove $H$, Clausen MR, Holtug $K$ Fermentation to short-chain fatty acids and lactate in Fermentation to short-chain fatty acids and lactate in variations versus variations caused by changes in fermented saccharides. Scand 7 Gastroenterol 1991; 26: 1285-94.

4 Rubinstein R, Howard AV, Wrong OM. In vivo dialysis of faeces as a method of stool analysis. IV. The organic anion component. Clin Sci 1969; 37: 549-64.

5 Ruppin H, Bar-Meir S, Soergel KH, Wood CM, Schmit MG. Absorption of short-chain fatty acids by the colon. Gastroenterology 1980; 78: 1500-7.

$6 \mathrm{McNeil}$ NI, Cummings JH, James WPT. Short chain fatty acid absorption by the human large intestine. Gut 1978; 19: 819-22.

7 Roediger WEW. Role of anaerobic bacteria in the metabolic welfare of the colonic mucosa in man. Gut 1980; 21: 793-8.

Breuer RI, Buto SK, Christ ML, Bean J, Vernia P, Paoluzi $\mathrm{P}$, et al. Rectal irrigation with short-chain fatty acids for distal ulcerative colitis. Preliminary report. Dig Dis Sci distal ulcerative

9 Scheppach W, Sommer H, Kirchner T, Paganelli GM Bartram P, Christl S, et al. Effect of butyrate enemas on the colonic mucosa in distal ulcerative colitis Gastroenterology 1992; 103: 51-6.

10 Senagore AJ, MacKeigan JM, Scheider M, Ebrom JS Short-chain fatty acid enemas: a cost-effective alternative in the treatment of nonspecific proctosigmoiditis. Dis Colon Rectum 1992; 35: 923-7.

11 Steinhart AH, Brzezinski A, Baker JP. Treatment of refractory ulcerative proctosigmoiditis with butyrate enemas. tory ulcerative proctosigmoiditis with

12 Vernia P, Cittadini M, Marcheggiano A, Frieri G, Caprilli $\mathrm{R}$, Valpiani D, et al. Short-chain fatty acid (SCFA) enemas in distal ulcerative colitis: a double-blind placebo-controlled in distal ulcerative colitis: a double-blind placebo-controlled study.

13 Breuer RI, Christ ML, Lashner BA, Soergel KH, Hanauer $\mathrm{SB}$, Harig JM, et al. Short chain fatty acid rectal irrigation herapy for left-sided ulcerative colitis: a randomized placebo-controlled clinical trial. Interim report. In: Shor Chain Fatty Acids. Binder HJ, Cummings J, Soergel KH eds. Falk Symposium No 73. Strasbourg, France, 1993 London: Kluwer Academic.

14 Roediger WEW. The colonic epithelium in ulcerative colitis: an energy deficiency disease? Lancet 1980; ii: 712-5.

15 Clausen MR, Mortensen PB. Kinetic studies on the metabolism of short-chain fatty acids and glucose by isolated rat colonocytes. Gastroenterology 1994; 106: 423-32. 
$16 \mathrm{Krebs} H A$, Henseleit $\mathrm{K}$. Untersuchungen über die harnstoffbildung im tierkörper. Hoppe-Seyler's $Z$ Physiol Chem 1932; 210: 33-66.

17 Roediger WEW, Truelove SC. Method of preparing isolated colonic epithelial cells (colonocytes) for metabolic studies. Gut 1979; 20: 484-8.

18 Stryer L, ed. Biochemistry. San Francisco: WH Freeman, 1975.

19 Vernia P, Gnaedinger A, Hauck W, Breuer RI. Organic anions and the diarrhea of inflammatory bowel disease. Dig Dis $S_{c i}$ 1988; 11: 1353-8.

20 Vernia P, Caprilli R, Latella G, Barbetti F, Magliocca FM, Cittadini M. Fecal lactate and ulcerative colitis. Gastroenterology 1988; 95: 1564-8.

21 Hove $\mathrm{H}$, Mortensen PB. Influence of intestinal inflammation (IBD) and small and large bowel length on fecal short-chain fatty acids and lactate. Dig Dis Sci 1995; 40: 1372-80.

22 Holtug K, Rasmussen HS, Mortensen PB. Short chain fatty acids in inflammatory bowel disease. The effect of bacterial fermentation of blood. Scand 7 Clin Lab Invest 1988; 48: $667-71$.

23 Roediger WEW, Heyworth M, Willoughby P, Piris J, Moore A, Truelove SC. Luminal ions and short chain fatty acids as markers of functional activity of the mucosa in ulceraas markers of functional activity of the mucc
tive colitis. $f$ Clin Pathol 1982; 35: 323-6.

24 Dankert J, Zijlstra JB, Wolthers BG. Volatile fatty acids in human peripheral and portal blood: quantitative determination by vacuum distillation and gas chromatography. Clin Chim Acta 1981; 110: 301-7.

25 Peters SG, Pomare EW, Fisher CA. Portal and peripheral blood short chain fatty acid concentrations after caecal lactulose instillation at surgery. Gut 1992; 33: 1249-52.

26 Morita A, Tsao D, Kim YS. Effect of sodium butyrate on alkaline phosphatase in HRT-18, a human rectal cancer alkaline phosphatase in HRT-18, a human rectal cancer

27 Gamet L, Daviaud D, Denis-Pouxviel C, Remesy C, Murat $J-C$. Effects of short-chain fatty acids on growth and differentiation of the human colon-cancer cell line HT29. Int f Cancer 1992; 52: 286-9.

28 Roediger WEW, Duncan A, Kapaniris O, Millard S. Reducing sulfur compounds of the colon impair colonocyte nutrition: implications for ulcerative colitis. Gastroenterology 1993; 104: 802-9.

29 Roediger WEW, Nance S. Selective reduction of fatty acid oxidation in colonocytes: correlation colitis. Lipids 1990; 25: 646-52.

30 Finnie IA, Taylor BA, Rhodes JM. Ileal and colonic epithelial metabolism in quiescent ulcerative colitis: increased glutamine metabolism in distal colon but no defect in glutamine metabolism in distal colon but no
butyrate metabolism. Gut 1993; 34: 1552-8.

31 Chapman MAS, Grahn MF, Boyle MA, Hutton M, Rogers $\mathrm{J}$, Williams NS. Butyrate oxidation is impaired in the colonic mucosa of sufferers of quiescent ulcerative colitis. Gut 1994; 35: 73-6. 